\title{
DETERMINANTES DE GUERRA \\ DE PREÇOS E CONLUIO NO TRANSPORTE AÉREO BRASILEIRO $\left.{ }^{(*)}\right)^{(*)}$
}

\author{
Ana Carolina Campana Nascimento ${ }^{* * *}$ \\ Wilson da Cruz Vieira ${ }^{* * *}$ \\ Marcelo José Braga ${ }^{* * * *}$
}

RESUMO: Este artigo tem como objetivo identificar possíveis padrões de guerras de preço e formação de conluio pelas companhias aéreas que operam no trecho Rio de Janeiro - São Paulo (GOL e TAM) e estimar as condições que facilitaram os dois fenômenos no período de 2002 a 2010. Para tanto, utilizaram-se a teoria dos jogos, a teoria econômica dos cartéis e os modelos logit como instrumentos de análise. Os resultados obtidos mostram que os fatores determinantes desses dois fenômenos são diferentes para cada companhia aérea: a TAM apresentou maior probabilidade de formação de conluio que a GOL no período analisado, enquanto esta última teve maior probabilidade de entrar em uma guerra de preços do que em um conluio. Além disso, as variáveis utilizadas neste estudo não conseguiram explicar a probabilidade da TAM praticar guerra de preços.

PALAVRAS-CHAVE: companhias aéreas; teoria dos jogos; cartel; modelo logit; Brasil.

CLASSIFACAÇÃO JEL: C71; L13; L93.

\footnotetext{
*Entrada em 14/02/2011 e aprovação em 05/11/2011.

** Os autores agradecem os comentários e sugestões de pareceristas anônimos.

*** Doutoranda em Economia Aplicada pela Universidade Federal de Viçosa e Professora Assistente do Departamento de Estatística da Universidade Federal de Viçosa. Contato: ana.campana@ufv.br.

**** Doutor em Economia Aplicada e Professor Associado do Departamento de Economia Rural da Universidade Federal de Viçosa. Contato: wvieira@ufv.br.

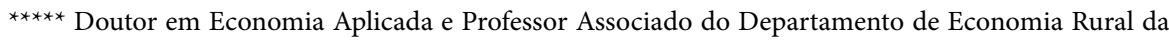
Universidade Federal de Viçosa. Contato: mjbraga@ufv.br.
} 


\section{DETERMINANTS OF PRICE WARS AND COLLUSION IN BRAZILIAN AIR TRANSPORTATION}

ABSTRACT: This paper aims to identify possible patterns of price wars and the formation of collusion by the airlines that operate in the route Rio de Janeiro - São Paulo (TAM and GOL) and estimate the conditions that facilitated the two phenomena in the period 2002 - 2010. To this end, we used game theory, economic theory of cartels and logit models as analytical tools. The results show that the determinants of these two phenomena are different for each airline: TAM had a higher probability of collusion formation than GOL in the analyzed period, while the latter was more likely to enter a price war than in collusion. Furthermore, the variables used in this study could not explain the probability of TAM practice price war.

KEYWORDS: airlines; game theory; cartel; logit model; Brazil. 


\section{INTRODUÇÃO}

O setor aéreo é um dos mais dinâmicos da economia mundial e possui atuação essencial em um cenário de interações globais, uma vez que proporciona intercâmbio ágil de pessoas e mercadorias dentro e entre as diferentes nações, viabilizando as relações econômicas e comerciais. No Brasil, esse setor torna-se ainda mais relevante dada a grande extensão territorial, a precariedade das malhas rodoviárias, a escassez de ferrovias e a baixa utilização da rede fluvial (Ferreira, 2007). Entretanto, apesar da sua importância, o setor aéreo brasileiro, assim como o mundial, caracteriza-se por ser concentrado, isto é, restringe-se a um número reduzido de ofertantes.

A concentração inerente a esse setor propicia a prática de condutas anticoncorrenciais. Dentre elas, destacam-se: a cooperação de preços entre as empresas aéreas, que é facilitada pelo pequeno seu número que atuam no setor; e o uso de preços predatórios (guerras de preços). Essas práticas anticoncorrenciais representam grandes desafios para as autoridades de defesa da concorrência, em virtude dos seus possíveis efeitos nocivos para os usuários.

No Brasil, a política de defesa da concorrência (política antitruste) só começou a ser utilizada de forma efetiva a partir da estabilização de preços propiciada pelo Plano Real, em 1994. A partir de então, o país passou a dispor de um aparato regulatório mais efetivo com relação à execução de políticas de controle de condutas e de estruturas de mercado (Turolla et al., 2006). As instituições governamentais responsáveis pela investigação antitruste no Brasil são: a Secretaria de Direito Econômico (SDE); o Conselho Administrativo de Defesa Econômica (CADE), ambos vinculados ao Ministério da Justiça; e a Secretaria de Acompanhamento Econômico (SEAE), vinculada ao Ministério da Fazenda.

Diante da configuração de um cenário pouco competitivo, as guerras de preços e formação de conluio em mercados aéreos têm sido objeto de estudo em diversas partes do mundo. Em 1999, a SDE abriu um processo, sob alegação de conduta combinada e uniforme, contra quatro companhias aéreas que operavam na ponte aérea Rio de Janeiro - São Paulo, devido a um aumento de preços no mesmo dia e em um mesmo percentual (10\%). Tal processo, julgado em 2004, resultou na condenação das companhias e no pagamento de multa. Esse fato foi estudado por Turolla et al. (2006) que, diferentemente da conclusão das autoridades, verificaram, por meio de um modelo estrutural empírico, que não houve conduta cooperativa entre as companhias aéreas, contrariando a decisão do CADE.

Recentemente, foram desenvolvidos os trabalhos de Ferreira (2007), que realizou uma análise descritiva das abordagens teóricas acerca das principais práticas de concorrência predatória verificadas no transporte aéreo; de Silveira e Oliveira (2008), 
que desenvolveram uma modelagem da competição em preços pós-liberalização na ligação Rio - São Paulo, buscando promover maior entendimento da racionalidade de guerras de preços no transporte aéreo. Além desses, Oliveira (2010) desenvolveu uma modelagem estrutural de demanda e oferta para o mercado de transporte aéreo, visando identificar a conduta competitiva das firmas, em situações de maior concentração ou participação na posse de slots.

Segundo Zhang e Round (2010), uma razão convencional para o início de uma guerra de preços é a quebra de um conluio. Porém, como o conluio é uma atividade ilegal, não é fácil comprovar tal comportamento. Além disso, determinar quando uma guerra de preços realmente começa e termina, e por quais razões, não é tarefa fácil. Dessa forma, diferentes teorias econômicas são utilizadas na tentativa de detectar tais fenômenos e, ainda, de encontrar suas causas e consequências.

$\mathrm{Na}$ literatura existem alguns trabalhos que visam identificar os determinantes de formação de conluio e guerras de preço no mercado aéreo. Morrison e Winston (1996) estudaram as características das empresas e do mercado que facilitaram a existência desses dois fenômenos para o caso americano entre os anos de 1978 e 1995. Além desses, Busse (2002) investigou a influência das características financeiras das empresas aéreas americanas, no período de 1985 a 1992, na disparada de guerras de preços. Mais recentemente, Zhang e Round (2010) analisaram os fatores determinantes destes dois fenômenos no mercado aéreo chinês no período de 2002 a 2004 . Para o caso brasileiro, porém, não se constatou a existência de estudos desse tipo.

Nesse sentido, este trabalho teve como objetivo identificar possíveis padrões (determinantes) de guerras de preços e formação de conluio pelas duas principais companhias aéreas brasileiras (TAM e GOL). Para tanto, foram estimados modelos logit utilizando dados mensais de operações na ponte aérea Rio de Janeiro - São Paulo, referentes às empresas aéreas TAM e GOL, no período de 2002 a 2010, buscando, assim, identificar as condições que facilitam os dois fenômenos.

A relevância deste estudo se justifica pela possibilidade de ampliação do conhecimento sobre a influência das condições de mercado e características das empresas que são propícias para o desencadeamento de guerras de preços e formação de conluio e, assim, contribuir para a identificação desses fenômenos por parte do órgão responsável pela regulação do setor.

Este trabalho está dividido em quatro seções, além desta introdução. A seção 2 descreve o setor em análise e, em especial, o mercado relevante para o estudo. Na seção 3 são apresentadas as teorias acerca do objeto de estudo, além dos modelos e dados utilizados na identificação dos determinantes de guerras de preços e conluio. Em seguida, abordam-se os resultados e discussões e, na quinta e última seção, as conclusões. 


\section{SETOR AÉREO BRASILEIRO}

Desde a década de 1990 o setor de transporte aéreo nacional vem passando por grandes mudanças estruturais, dentre elas, a gradual eliminação das barreiras à entrada de novas companhias e a desregulamentação desse mercado. Essas duas mudanças visaram ampliar a competição entre as empresas que atuam nesse setor. Porém, conforme ressaltou Vassallo (2010), esse processo trouxe a percepção de que a competição plena não seria tão saudável às companhias existentes, uma vez que essas estavam se recuperando de um período de alta instabilidade devido às crises econômicas, o que contribuiu para a ocorrência de crises financeiras e falências no setor, como as da Varig, VASP e Transbrasil.

Desde então, o transporte aéreo no Brasil cresceu muito, existindo, atualmente, cerca de 2.498 aeroportos, incluindo as áreas de desembarque, o que representa o segundo maior número de aeroportos em todo o mundo, atrás apenas dos Estados Unidos. Além disso, o Brasil sedia importantes aeroportos internacionais, servindo de destino de uma série de rotas aéreas internacionais.

Segundo dados do Anuário do Transporte Aéreo de 2010 ( $\left.\mathrm{A}^{\mathrm{NA}} \mathrm{C}, 2010\right)$, entre os anos de 2002 e 2010, o setor aéreo brasileiro apresentou um crescimento médio anual de, aproximadamente, 9,68\%. No mesmo período, a principal ligação do setor, a ponte aérea Rio-São Paulo, apresentou um crescimento médio menor, de aproximadamente $1,98 \%$, o que era esperado, dada a densidade de passageiros transportados nessa rota e a estabilidade desse mercado. Por outro lado, no mesmo período, o transporte rodoviário brasileiro cresceu anualmente, em média, apenas cerca de 0,45\% (ANTT, 2008, 2007, 2006, 2005, 2004, 2003, 2002, 2001). Esse crescimento do setor aéreo foi motivado pela entrada de novas companhias aéreas no mercado (GOL, em 2001, e Azul, em 2008), além da modernização das já existentes, o que acarretou aumento do número de assentos disponíveis e, devido ao baixo custo apresentado pelas novas empresas, redução nas tarifas praticadas no mercado.

Dentre as diversas linhas de operação no Brasil, merece destaque o trecho Rio de Janeiro-São Paulo, por se tratar da ligação dos principais centros industriais do país, pela densidade de tráfego, bem como pela presença de todas as maiores companhias aéreas nacionais. Assim, essa ligação, mais precisamente a ligação Congonhas-Santos Dumont, foi delimitada como o mercado relevante para a análise em questão. Dessa forma, os determinantes dos comportamentos anticoncorrenciais investigados neste trabalho tomaram como base o transporte regular de passageiros na ponte aérea Rio de Janeiro - São Paulo, mais especificamente a ligação Congonhas - Santos Dumont.

Essa ligação é reconhecidamente a mais importante do transporte aéreo brasileiro. É responsável pela maior densidade de tráfego, bem como de lucro, quando comparada às demais rotas nacionais. Caracteriza-se pelas viagens tipicamente por motivos de 
negócios, ligando os dois principais centros industriais do país e, por ser um mercado estratégico, as empresas aéreas brasileiras normalmente adotam ações específicas para ele como, por exemplo, campanhas publicitárias, anúncios de promoções, e, até recentemente, as decisões de reajustes das tarifas das outras ligações do país eram feitas de forma descasada com as decisões relativas a esse trecho (Turolla et al., 2006).

Em 2001, a GOL iniciou suas operações na linha Galeão - Congonhas, o que acabou gerando efeitos importantes à ponte aérea, sendo, de certa forma, responsável pela "guerra de preços" observada nos meses seguintes naquele mercado (Turolla et al., 2006). Apesar dos efeitos gerados, a ligação Congonhas-Santos Dumont, ainda se destaca como a rota com maior quantidade de assentos oferecidos e quantidade de voos. No mercado doméstico, essa ligação representou 5,0\% dos assentos oferecidos e 4,7\% dos voos realizados em 2010 (ANAC, 2010).

Nesta ligação atuam as companhias aéreas AVIANCA, GOL, Pantanal, TAM e WEBJET, sendo as mesmas responsáveis por $9,3 \% ; 43,0 \% ; 0,0 \% ; 47,5 \%$; e $0,3 \%$ da parcela de mercado no ano de 2010, respectivamente. Esses valores mostram a alta concentração nesse trecho, sendo as companhias aéreas GOL e TAM responsáveis por mais de $90 \%$ do transporte de passageiros (ANAC, 2010).

\section{METODOLOGIA}

\subsection{GUERRA DE PREÇOS E PREÇOS DE CONLUIO - ASPECTOS TEÓRICOS E EMPÍRICOS}

Pode-se definir conluio entre firmas concorrentes e independentes, de um mesmo mercado relevante, como uma combinação de preços e/ou quantidades ou qualquer outra variável que permita o exercício do poder de mercado, com o objetivo de eliminar ou diminuir a concorrência entre seus participantes, propiciando, assim, um aumento dos lucros. O objetivo principal é atuar como se fosse um monopólio, mas, enquanto no monopólio a decisão cabe apenas a um ofertante, em um conluio a decisão, apesar de conjunta, é consciente de que o lucro das firmas depende do comportamento do todos os ofertantes da indústria (Flores, 2007).

Os acordos surgem quando as firmas percebem que a interação entre elas, de forma cooperativa, pode levar à obtenção de lucros acima daqueles alcançados caso não houvesse cooperação. Mais ainda, o fato de haver interdependência em suas ações, isto é, as ações de uma firma interferindo nos resultados das demais, há incentivos para comportamento estratégico que permite a maximização conjunta de lucros. Nesse caso, a interação estratégica entre as firmas no processo de tomada de decisão, por meio de conluio, pode ser modelada por meio de instrumental teórico e analítico oferecido pela teoria dos jogos. 
Segundo Osborne e Rubinstein (1994), a teoria dos jogos é um conjunto de ferramentas criadas para auxiliar o entendimento dos fenômenos observados quando os tomadores de decisão (jogadores) interagem e há conflito de interesses entre eles. Um jogo é caracterizado como um conjunto de regras que descrevem a realidade, definindo os agentes econômicos (jogadores), as possíveis ações (estratégias) desses agentes e um conjunto de informações que orientam os agentes nas decisões racionais e maximizadoras de resultados.

Os jogos podem ser divididos em dois ramos: jogos cooperativos e não cooperativos (Kreps, 1990). Nos cooperativos, os participantes desejam maximizar o resultado da coalizão e, para isso, colaboram uns com os outros. Nos não cooperativos, a unidade de análise é o indivíduo que se preocupa em maximizar seus próprios resultados, dentro das regras do jogo, qualquer que seja o resultado coletivo.

Especificamente, um conluio pode ser modelado como um equilíbrio de um jogo repetido infinitas vezes, em que, a cada rodada do jogo, vista de forma isolada, as firmas teriam incentivos a agir de forma oportunista, quebrando o acordo. Em um jogo deste tipo, a solução de equilíbrio pode ser caracterizada como aquela em que os payoffs obtidos pelas firmas são maiores que aqueles obtidos na solução do equilíbrio estático não cooperativo (equilíbrio de Nash), porém menores que uma solução de monopólio.

Nesse caso, as firmas são suficientemente pacientes, isto é, consideram mais importantes os lucros futuros em relação aos lucros correntes. Caso alguma firma se desvie do acordo, estará sujeita à retaliação ou punição, que deve ser efetiva em prevenir as rivais de desviarem. Para ser efetiva, a retaliação deve implicar uma perda significativa à firma que desviou em comparação aos ganhos obtidos pelo comportamento oportunista. Assim, a essência do incentivo à permanência do acordo (conluio) é o de comparar os ganhos imediatos de um desvio, com as perdas recebidas pela punição sofrida, caso o comportamento oportunista seja identificado pelas demais firmas.

As punições podem tomar diferentes formas, umas mais efetivas do que outras, e quanto mais efetiva, maiores os preços de conluio sustentados. Algumas propostas de punição são apresentadas na literatura, podendo-se citar Friedman (1971), que sugeriu uma estratégia de "gatilho", na qual as empresas passariam a agir, definitivamente, de forma competitiva a partir da deteç̧ão de algum desvio do conluio, caso do "retaliador permanente"; Porter (1983) e Green e Porter (1984), por sua vez, sugeriram uma punição menos rigorosa, em que a punição (período competitivo) seria temporária, perdurando a solução competitiva por apenas um período determinado de tempo e, depois, retornando à solução de conluio. Porém, de acordo com Abreu, Pearce e Stacchetti (1986), as estratégias de punição ótimas deveriam ser mais severas do que no caso de Green e Porter (1984), mas que dure menos tempo para voltar à solução de conluio - na literatura essa punição é identificada como “stick and carrot". Neste caso, há uma 
punição mais severa quando o desvio é detectado (fase stick) e, em seguida, volta-se à solução de conluio, para que as firmas sejam incentivadas a punir (fase carrot), desde que as firmas não tenham se desviado, pois, caso contrário, a fase stick perdura.

Uma questão importante não contemplada acima, mas que condiciona a implementação de um acordo, é a disponibilidade de informação das firmas. Na prática, as firmas não possuem informação perfeita sobre todas as variáveis relevantes para tomada de decisões, sendo, então, observadas fases de guerras de preços (punição) em mercados em que há suspeita de conluio. Segundo Busse (2002), uma guerra de preços é um período no qual as empresas determinam preços significativamente menores que os preços de mercado, geralmente implicando em mudanças de estratégias de uma ou de um conjunto de empresas. Zhang e Round (2010), por sua vez, salientaram que este comportamento, normalmente, é devido a uma quebra de conluio, porém um guerra de preços, segundo Zeidan e Resende (2010), pode ser também devido às flutuações na demanda, capacidade produtiva, choques de custos ou mesmo comportamento estratégico das firmas.

A identificação de uma guerra de preços, bem como a percepção de formação de conluio, nem sempre são fáceis, devido à falta de informação por parte das firmas e a subjetividade e arbitrariedade do processo, bem como ao fato de que ambas as práticas não são permitidas por ferirem o bem estar econômico. Assim, a determinação empírica desses fenômenos varia entre os autores; por exemplo, Morrison e Winston (1996), ao analisar o mercado de aviação, definiram guerra de preços comparando o preço médio de um mês com o do mês anterior; se a queda no preço fosse maior que $20 \%$, haveria guerra de preços, e um aumento no preço maior que 5\% em relação ao mês anterior identificaria o fim de uma guerra de preços em um determinado mercado.

Ross (1997) utilizou um teste estatístico para diferenciar a média de preços do trimestre do ano atual com o trimestre do ano anterior. Heil e Helsen (2001) descreveram um conjunto de condições qualitativas que poderiam ser usadas para identificar guerra de preços, podendo-se citar:

a) As ações e reações em grande parte envolvem o concorrente em vez de o consumidor;

b) Interação de preços é indesejável para os concorrentes;

c) Não concorrentes deliberadamente provocam uma guerra de preços;

d) A violação das normas do comportamento de preços da indústria;

e) A direção do preço é de diminuição, mas esse comportamento de preços não é sustentável.

As definições apresentadas acima possuem algumas fragilidades. No caso da abordagem de Heil e Helsen (2001), a maioria das informações requeridas pode não 
ser facilmente observada e, portanto, torna-se difícil a definição de guerras de preços com base em observações dessas condições. No caso de Morrison e Winston (1996), ao considerar apenas a análise de variação dos preços, pode-se estar incorrendo em erros de especificação, o que implicaria em erros de diagnóstico. Assim, buscando reduzir a probabilidade de ocorrência desse tipo de erro, mas reconhecendo que se esta baseando em uma análise de preços e custos, dos quais não se tem plena observabilidade, neste trabalho, as variações dos preços foram ajustadas por variações no custo, como proposto por Zeidan e Resende (2010), de forma que as quedas de preço acompanhadas de queda nos custos não indicarão início de guerra de preços.

No caso de empresas oligopolistas, como as aéreas, o dilema de "competir" para aumentar sua fatia de mercado ou "cooperar" para obter lucros maiores é recorrente. Dessa forma, ao se tornarem passivas ao cooperar, limitam sua produção e praticam preços mais elevados, obtendo lucros maiores. Tais práticas, competição e cooperação, foram modeladas neste trabalho a partir da definição empírica proposta por Zeidan e Resende (2010), que estabeleceram como período de guerra de preços aquele em que $\Delta$ preço $-\Delta c u s t o>5 \%$, em relação ao preço do período anterior e enquanto os preços se mantiverem em queda, ou não crescerem acima de $0,5 \%$ do preço que iniciou a guerra.

Com relação à definição de conluio, Levenstein e Suslow (2006) definiram a formação de preços de colusão como uma situação em que o preço médio da passagem aérea aumenta mais de $20 \%$ em relação ao mês anterior. O comportamento de colusão é considerado bem sucedido até que as tarifas médias das passagens aéreas diminuam em $5 \%$ ou mais em relação ao mês anterior. Porém, essa definição de colusão está sujeita à arbitrariedade. No Brasil, uma elevação de $10 \%$ nos preços, pelas companhias aéreas, em um mesmo dia no ano de 1999, foi objeto de investigação e punição das companhias envolvidas.

Desse modo, a definição de períodos colusivos ou de coordenação de preços foi definida, neste trabalho, com base em uma elevação de preços superior a 10\%, dado que esse foi o critério utilizado em 1999 para punição das empresas aéreas.

\subsection{BASE DE DADOS E MODELAGEM EMPÍRICA}

A análise realizada neste trabalho utilizou dados econômicos e estatísticos mensais das duas principais empresas aéreas nacionais (TAM e GOL), que operaram na linha Congonhas-Santos Dumont no período entre março de 2002 e setembro de 2010, totalizando 132 observações. A base de dados utilizada é composta por informações obtidas junto à Agência Nacional de Aviação Civil (ANAC).

Para explicar a probabilidade de ocorrência de guerras de preços e conluio entre as principais companhias aéreas que operam na linha Congonhas-Santos Dumont e 
identificar seus determinantes foram estimados, para cada empresa, modelos Logit ${ }^{1}$ cujas variáveis dependentes são baseadas nas definições de guerra de preço e conluio apresentadas anteriormente.

No primeiro modelo, que explica a ocorrência de guerra de preços, a variável dependente $\left(y_{g p}\right)$ foi definida como:

$$
y_{g p_{i t}}=\left\{\begin{array}{l}
1, \text { se a empresa aérea } i \text { está em guerra de preços no período } t . \\
0, \text { caso contrário. }
\end{array}\right.
$$

De forma análoga, no modelo que visa identificar os determinantes da formação de um conluio, a variável dependente $\left(y_{c o}\right)$ foi definida por:

$$
y_{c o_{i t}}=\left\{\begin{array}{l}
1, \text { se a empresa aérea } i \text { está em conluio no período } t . \\
0, \text { caso contrário. }
\end{array}\right.
$$

As variáveis explicativas são referentes ao mercado em estudo e foram selecionadas com base no conhecimento teórico de guerras de preços e conluio, apresentados em estudos anteriores ${ }^{2}$.

Desse modo, propuseram-se os seguintes modelos Logit:

$$
P\left(y_{g p_{i t}}=1 \mid \mathbf{x}_{\mathbf{i t}},{ }^{2}\right)=\Lambda\left(\mathbf{x}_{\mathbf{i t}}^{2}\right)
$$

e

$$
P\left(y_{c o_{i t}}=1 \mid \mathbf{x}_{\mathbf{i t}},{ }^{2}\right)=\Lambda\left(\mathbf{x}_{\mathbf{i t}}^{2}\right)
$$

para explicar a ocorrência de guerra de preços e conluio, respectivamente.

Nos dois casos, tem-se que $\Lambda$ (.) é a função de distribuição de probabilidade acumulada logística, representada por:

$$
\Lambda\left(X_{i} \beta\right)=\frac{1}{1+e^{-X_{i} \beta}}=\frac{e^{X_{i} \beta}}{1+e^{X_{i} \beta}} .
$$

Como esses são modelos não lineares, a estimação dos coeficientes deve ser feita pelo método de máxima verossimilhança.

\footnotetext{
${ }^{1}$ Para maiores detalhes dos modelos Logit, ver, por exemplo, Hill, Griffiths e Judge (2003), Maddala (1992) ou Cameron e Trivedi (2005).

${ }^{2}$ Por exemplo, citam-se Zhang e Round (2010); Ferreira (2007); Busse (2002); Heil e Helsen (2001); e Morrison e Winston (1996).
} 
As variáveis explicativas utilizadas foram as mesmas para os dois modelos, uma vez que uma guerra de preços pode ser vista como um contraponto de conluio de preços.

Deste modo, a equação estimada tem a seguinte forma:

$$
\mathbf{x}_{\mathbf{i t}}^{2}=\beta_{0}+\beta_{1} m k s_{i t}+\beta_{2} \text { pib }_{t}+\beta_{3} \text { ppas }_{i t}+\beta_{4} \text { pmec }_{t}+\beta_{5} \text { freqc }_{t}+\beta_{6} c o_{i t-1}+\beta_{7} g p_{i t-1}+\varepsilon_{i t},
$$

Onde:

$m k s_{i t}$ é o market share (parcela de mercado) da companhia aérea $i$ no mês $t$; pib $b_{t}$ é o Produto Interno Bruto (PIB) brasileiro, a preços de mercado, no período $t$; $n_{\text {pas }}$ é o número de passageiros ${ }^{3}$ transportados pela companhia aérea $i$ no mês $t$; $\operatorname{pmec}_{t}$ é o preço médio das companhias aéreas concorrentes no mês $t$; freqc $_{i t}$ é a frequência média mensal de voo das companhias aéreas concorrentes; $c o_{i t-1}$ é uma variável $d u m m y$ que indica se a companhia aérea $i$ estava em conluio no período $t-1$;

$g p_{i t-1}$ é uma variável dummy que indica se a companhia aérea $i$ participava de uma guerra de preços no período $t-1$;

$\varepsilon_{i t}$ é o termo de erro do modelo.

Sabe-se que mercados concentrados são mais propensos à formação de conluio do que mercados menos concentrados e que a concentração do setor é um fator relevante no comportamento dos preços. Neste caso, a variável explicativa é a parcela de mercado de cada companhia aérea em um determinado período de tempo $\left(m k s_{i t}\right)$, medida em função do número de assentos oferecidos. Espera-se, portanto, que a mesma influencie positivamente a probabilidade de formação de conluio e, negativamente, a disparada de uma guerra de preços.

Rotemberg e Saloner (1986) sugeriram que as guerras de preço teriam como principal motivo a elevação da demanda devido à expansão da economia. Assim, para tentar captar tal efeito, incluiu-se no modelo a variável Produto Interno Bruto (PIB), expresso em milhões de reais, disponível no site do Banco Central do Brasil (BACEN) ${ }^{4}$, como uma proxy do índice da Atividade Econômica Brasileira. Como sugerem os autores anteriormente citados, espera-se que essa variável tenha influência positiva na probabilidade de ocorrência de guerras de preços, uma vez que os ganhos advindos do desvio do conluio são maiores quando a demanda (expansão econômica) está alta. $\mathrm{O}$ contrário é esperado em relação à formação de conluio.

\footnotetext{
${ }^{3}$ Como o número de passageiros é uma variável altamente correlacionada ao PIB, não foram utilizadas essas variáveis conjuntamente em um mesmo modelo.

${ }^{4}$ Base de dados do Banco Central do Brasil (http://www.bcb.gov.br/).
} 
A demanda por passagens, variável extremamente relevante quando se pretende identificar a ocorrência de práticas predatórias em um mercado, pode ser medida também através do número de passagens vendidas (passageiros transportados npas). Assim como o baixo índice de atividade econômica, em períodos de baixa procura há maior possibilidade de ocorrência de guerras de preços e menor probabilidade de formação de conluio.

Espera-se, ainda, que quanto maior a presença das companhias concorrentes, medida pela frequência média mensal de voo das companhias aéreas concorrentes $\left(\right.$ freqc $\left.c_{i t}\right)$, menor seja a demanda da companhia aérea em questão e quanto menor a demanda, maior probabilidade de ocorrência de guerras de preços e menor probabilidade de formação de conluio. Essa variável foi construída dividindo-se o número total de frequências das companhias concorrentes pelo número de companhias concorrentes.

Além dessas, a literatura sugere que o fato de uma companhia aérea estar em conluio em um determinado período aumenta a probabilidade de a mesma praticar guerra de preços no período seguinte, dado que uma razão convencional para o início de uma guerra de preços é a quebra de um conluio (Zhang e Round, 2010).

Para se analisar a magnitude do efeito de cada variável na probabilidade de formação de conluio ou início de uma guerra de preços, o exame dos coeficientes não é o mais indicado. Essa análise é feita pelo cálculo do efeito marginal (EM). O EM de uma variável explicativa mede o impacto da mesma sobre a probabilidade de ocorrência de um evento, nesse caso, $P\left(y_{g p}=1\right)$ e $P\left(y_{c o}=1\right)$.

Para variáveis contínuas o EM é dado pela derivada da função em relação à variável, isto é,

$$
\frac{\partial P}{\partial X_{j}}=\hat{P}(1-\hat{P}) \hat{\beta}_{j}=\Lambda\left(X_{i} \hat{\beta}\right)\left[1-\Lambda\left(X_{i} \hat{\beta}\right)\right] \hat{\beta}_{j}
$$

O EM pode ser calculado no ponto médio das variáveis explicativas (efeito marginal médio) ou em pontos específicos da amostra (valores específicos das variáveis explicativas). Neste trabalho, optou-se pelo cálculo no ponto médio da amosta.

\section{RESULTADOS E DISCUSSÃO}

Algumas estatísticas descritivas das variáveis empregadas na estimação dos modelos logit para a explicação da ocorrência de guerras de preço e conluio na ligação Rio - São Paulo, no período de março de 2002 a setembro de 2010, estão dispostas na Tabela 1.

Observou-se que a TAM é a maior detentora de parcela de mercado $(m k s)$ em todo o período em análise, tendo, em média, 39\% da parcela de mercado. A GOL 
teve um crescimento muito grande nos últimos anos. Suas atividades iniciaram-se no final de 2001 e, em março de 2003, ela detinha 7\% dos assentos fornecidos nessa ligação. Essa companhia foi responsável por um grande investimento em marketing e programa de milhagem, fazendo com que em 2010 ela alcançasse um total de $48 \%$ dos assentos oferecidos para a ligação em estudo.

Tabela 1 - Estatísticas descritivas das variáveis explicativas de guerra de preço e conluio, março de 2002 a setembro de 2010

\begin{tabular}{|c|c|c|c|c|c|}
\hline \multicolumn{2}{|l|}{ Variáveis } & Média & Desvio-Padrão & Mínimo & Máximo \\
\hline \multirow{2}{*}{$m k s(\%)$} & GOL & 30,00 & 9,76 & 7,15 & 48,23 \\
\hline & TAM & 39,00 & 7,00 & 25,00 & 59,00 \\
\hline $\begin{array}{l}\text { PIB } \\
\text { (milhões R\$) }\end{array}$ & & $203.618,83$ & $55.253,80$ & $115.637,00$ & $314.922,00$ \\
\hline \multirow{2}{*}{ npas $\left(\mathrm{n}^{\circ}\right)$} & GOL & $87.376,20$ & $28.921,49$ & $17.635,00$ & $149.921,00$ \\
\hline & TAM & $110.664,34$ & $26.586,89$ & $49.058,00$ & $163.691,00$ \\
\hline \multirow{2}{*}{ pmec (R\$) } & GOL & 151,21 & 56,34 & 51,81 & 253,06 \\
\hline & TAM & 221,27 & 63,86 & 88,90 & 583,07 \\
\hline \multirow{2}{*}{$\begin{array}{l}\text { freqc } \\
\text { (Km voados) }\end{array}$} & GOL & $880.450,43$ & $214.483,91$ & $601.520,00$ & $1.529 .350,00$ \\
\hline & TAM & $757.891,71$ & $159.533,94$ & $437.330,00$ & $1.216 .180,00$ \\
\hline
\end{tabular}

Fonte: Dados da pesquisa.

De forma análoga, o número de passageiros transportados pela TAM foi superior ao da GOL em todo o período, tendo a TAM transportado, em média, 110.664 passageiros ao mês, enquanto a GOL é responsável pelo transporte médio mensal de 87.376 passageiros.

No que se refere aos preços médios das concorrentes (mpec), entre 2002 e 2010, as concorrentes da TAM apresentaram uma média de preços superior aos da GOL. Considerando-se que as concorrentes de ambas as companhias são as mesmas, tem-se que, nesse período, a média de preços praticada pela GOL foi maior que a da TAM. Além disso, a frequência de voos das concorrentes da TAM, medida pela média da quilometragem voada, foi inferior às das concorrentes da GOL, evidenciando, assim, a maior frequência da TAM nessa ligação.

A Tabela 2 reproduz a estimação final dos parâmetros dos modelos que visam identificar os determinantes da formação de conluio e guerra de preços por parte da companhia GOL, na ligação Rio-São Paulo, no período em análise.

Pode-se notar, pela Tabela 2, que, no modelo para explicar a formação de conluio, a estatística razão de verossimilhança (LR) foi de $-38,074$, significativa a $1 \%$, indicando 
que, conjuntamente, os regressores são estatisticamente diferentes de zero e, assim, são capazes de explicar tal fenômeno. O Count $R^{2}$ indica que o modelo previu corretamente $84,31 \%$ das observações, indicando bom ajuste.

Tabela 2 - Resultados da estimação dos modelos de conluio e guerra de preços para a companhia aérea GOL, 2002 a 2010

\begin{tabular}{|c|c|c|c|c|c|c|}
\hline \multirow[b]{2}{*}{ Variável } & \multicolumn{3}{|c|}{ Variável dependente: Conluio } & \multicolumn{3}{|c|}{ Variável dependente: Guerra de Preços } \\
\hline & Coeficiente & $\begin{array}{l}\text { Desvio } \\
\text { Padrão }\end{array}$ & EM & Coeficiente & $\begin{array}{l}\text { Desvio } \\
\text { Padrão }\end{array}$ & EM \\
\hline$m k s$ & $-0,177838^{* *}$ & 0,073739 & $-0,014998^{\star * *}$ & $-0,159331^{\star * *}$ & 0,062637 & $-0,037972^{\star * *}$ \\
\hline pib & $0,000012^{\mathrm{NS}}$ & 0,000009 & $0,000001^{\mathrm{NS}}$ & - & - & - \\
\hline npas & - & - & - & $0,000048^{* * *}$ & 0,000019 & $0,000011^{\star * *}$ \\
\hline pmec & $0,014794^{* *}$ & 0,007128 & $0,001248^{\star * *}$ & $-0,010842^{*}$ & 0,005764 & $-0,002584^{*}$ \\
\hline freqc & $-0,000002^{*}$ & 0,000001 & $-1,99 \mathrm{E}-07^{*}$ & - & - & - \\
\hline$c o_{t-1}$ & - & - & - & $1,055414^{*}$ & 0,599206 & $0,257438^{*}$ \\
\hline$g p_{t-1}$ & $1,224522^{\star *}$ & 0,595621 & $0,116773^{\star}$ & - & - & - \\
\hline Constante & - & - & - & $1,613757^{\mathrm{NS}}$ & 1,692016 & - \\
\hline \multicolumn{2}{|c|}{$L R=-38,074$} & & & \multicolumn{3}{|l|}{$L R=-63,035$} \\
\hline \multicolumn{2}{|c|}{$\chi^{2}=26,69^{\star * *}$} & & & \multicolumn{3}{|l|}{$\chi^{2}=11,38^{*}$} \\
\hline \multicolumn{2}{|c|}{ Count $R^{2}=84,31 \%$} & & & \multicolumn{3}{|c|}{ Count $R^{2}=69,61 \%$} \\
\hline \multicolumn{2}{|c|}{$P\left(y_{c o}\right)=0,0930$} & & & \multicolumn{3}{|c|}{$P\left(y_{g p}\right)=0,3919$} \\
\hline
\end{tabular}

Notas: ${ }^{(*)}$ significativo a $10 \% ;{ }^{(* *)}$ significativo a $5 \% ;{ }^{(* * *)}$ significativo a $1 \%$; (NS) não significativo.

Fonte: Dados da pesquisa.

A análise individual dos coeficientes estimados mostra que apenas o coeficiente associado à variável Produto Interno Bruto (PIB) não foi significativo em nível 10\%, sendo as demais variáveis importantes para a explicação desse fenômeno para a amostra analisada. A parcela de mercado $(m k s)$, apesar de significativa, apresentou sinal diferente do que era esperado. Uma possível explicação para esse fato é que, no período analisado, a GOL praticou por inúmeras vezes guerra de preços buscando ganhar mercado. Dessa forma, mesmo que a parcela de mercado fosse maior, não havia interesse dela em participar de um conluio. A variável pmec apresentou sinal de acordo com o esperado e influência significativa na decisão de formação de conluio entre a GOL e as demais companhias aéreas. Considerando o valor médio de $\mathrm{R} \$ 151,25 \mathrm{da}$ variável pmec, um aumento de $\mathrm{R} \$ 1,00$ no custo médio da passagem das concorrentes da GOL levaria a um aumento de 0,12 pontos percentuais (p.p.) na probabilidade de formação de conluio por parte dessa empresa. Apesar de significativa, a variável freqc apresentou valores de coeficiente e efeito marginal muito próximos a zero, sugerindo, 
assim, pouca influência na decisão de formação de conluio. A variável mais importante para explicar a probabilidade da GOL participar de um conluio foi $g p_{t-1}$, ou seja, o fato da GOL estar participando de uma guerra de preços em um determinado período aumenta a probabilidade de ela participar de um conluio no período seguinte em 11,68 p.p. De modo geral, a probabilidade de formação de conluio por parte da companhia aérea GOL, estimada pelo modelo, é de aproximadamente 9,30\%, no período analisado (Tabela 2).

No modelo que explica a participação da GOL em uma guerra de preços, tem-se que a estatística razão de verossimilhança (LR) foi significativa a $10 \%$, isto é, conjuntamente, os regressores são capazes de explicar a participação em uma guerra de preços por parte da GOL. Nesse modelo foram previstas corretamente aproximadamente $70 \%$ das observações (Count $R^{2}$ ).

Diferentemente do modelo anterior, neste considerou-se o termo constante e as variáveis número de passageiros (npas) e o fato de a companhia estar em conluio no período anterior $\left(c o_{t-1}\right)$ e não se incluiu a variável freqc. Individualmente, apenas o termo constante não se apresentou significativo. A variável parcela de mercado $(m k s)$ foi significativa em nível de $10 \%$ e apresentou sinal de acordo com a expectativa teórica. Esse resultado difere daqueles encontrados por Zhang e Round (2010) e Levinstein e Suslow (2006). Estes autores argumentaram que, embora a teoria econômica sugira que a colusão seja mais provável em mercados mais concentrados, esse resultado não foi encontrado em todos os modelos estimados. Por outro lado, a variável número de passageiros (npas), apesar de significativa, não apresentou sinal negativo como esperado. Este resultado não corrobora com aqueles encontrados por Green e Porter (1984) e Zhang e Round (2010), que sugerem maior probabilidade de guerras de preços em mercados de baixa demanda.

A variável preço médio das companhias concorrentes ( $p m e c)$ foi significativa em nível de $10 \%$ e, também, apresentou sinal de acordo com a expectativa teórica.

Observa-se, ainda, que, para o período analisado, o fato de a GOL estar em conluio em um determinado período foi a variável mais relevante em explicar a probabilidade de a empresa estar em uma guerra de preços no período seguinte. Assim, o fato de a GOL estar participando de um conluio em um determinado período, faz com que aumente, em média 25,74 p.p. a probabilidade de disparada de guerra de preços por parte dessa companhia no período seguinte, ceteris paribus. De forma análoga, um aumento de uma unidade no número de passageiros da GOL aumenta a probabilidade de ocorrência de guerra de preços em 0,001 p.p. Por outro lado, um aumento de $\mathrm{R} \$ 1,00$ no valor médio das passagens das concorrentes reduz essa probabilidade em 0,26 p.p. De modo geral, a probabilidade de disparada de guerra de preços por parte da companhia aérea GOL, estimada pelo modelo, é de aproximadamente 39,19\%, no período analisado (Tabela 2). 
Nota-se, então, uma maior propensão da GOL a entrar em uma guerra de preços do que em um conluio (Tabela 2). O setor viveu um grande período de guerra de preços após a entrada da GOL, empresa líder em baixo custo nesse setor, e não foi diferente com essa ligação. Nesta ocasião, as companhias aéreas ofereceram descontos em diferentes dias e horários na tentativa de reagir à entrada da GOL, como forte concorrente e de baixo custo no setor.

Modelos semelhantes foram estimados para tentar identificar os determinantes da formação de conluio e guerra de preços por parte da companhia TAM, na ligação Rio de Janeiro - São Paulo, no período de março de 2002 a setembro de 2010. Os resultados da estimação final dos parâmetros dos modelos são apresentados na Tabela 3.

Tabela 3 - Resultados da estimação dos modelos de conluio e guerra de preços para a companhia aérea TAM, 2002 a 2010

\begin{tabular}{|c|c|c|c|c|c|c|}
\hline \multirow[b]{2}{*}{ Variável } & \multicolumn{3}{|c|}{ Variável dependente: conluio } & \multicolumn{3}{|c|}{ Variável dependente: guerra de preços } \\
\hline & Coeficiente & $\begin{array}{l}\text { Desvio- } \\
\text { Padrão }\end{array}$ & EM & Coeficiente & $\begin{array}{l}\text { Desvio- } \\
\text { Padrão }\end{array}$ & EM \\
\hline$m k s$ & $0,052694^{\mathrm{NS}}$ & 0,072136 & $0,006237^{\mathrm{NS}}$ & $-0,016781^{\mathrm{NS}}$ & 0,0546166 & $-0,003734^{\mathrm{NS}}$ \\
\hline pib & $-0,000006^{\mathrm{NS}}$ & 0,000010 & $-7,29 \mathrm{E}-07^{\mathrm{NS}}$ & $1,16 \mathrm{E}-07^{\mathrm{NS}}$ & 0,000008 & $2,59 \mathrm{E}-07^{\mathrm{NS}}$ \\
\hline npas & - & - & - & - & - & - \\
\hline pmec & $-0,009715^{* *}$ & 0,005017 & $-0,001144^{* *}$ & $-0,001169^{\mathrm{NS}}$ & 0,003314 & $-0,000260^{\mathrm{NS}}$ \\
\hline freqc & $-0,000005^{\mathrm{NS}}$ & 0,000001 & $-5,83 \mathrm{E}-08^{\mathrm{NS}}$ & - & - & - \\
\hline$c o_{t-1}$ & - & - & - & $1,479483^{* *}$ & 0,609933 & $0,3520927^{* *}$ \\
\hline$g p_{t-1}$ & $-0,339524^{\mathrm{NS}}$ & 0,623922 & $-0,038607^{\mathrm{NS}}$ & - & - & - \\
\hline Constante & - & - & - & - & - & - \\
\hline \multicolumn{4}{|c|}{$L R=-41,256$} & \multicolumn{3}{|c|}{$L R=-62,024$} \\
\hline \multicolumn{4}{|c|}{$\chi^{2}=37,12^{\star * *}$} & \multicolumn{3}{|c|}{$\chi^{2}=15,63^{\star * *}$} \\
\hline \multicolumn{4}{|c|}{ Count $R^{2}=85,29 \%$} & \multicolumn{3}{|c|}{ Count $R^{2}=69,61 \%$} \\
\hline \multicolumn{4}{|c|}{$P\left(y_{c o}=1\right)=0,1363$} & \multicolumn{3}{|c|}{$P\left(y_{g p}=1\right)=0,3343$} \\
\hline
\end{tabular}

Notas: ${ }^{(*)}$ significativo a $10 \% ;{ }^{(* *)}$ significativo a $5 \% ;{ }^{(* * *)}$ significativo a $1 \% ;{ }^{(\text {(N) })}$ não significativo.

Fonte: Dados da pesquisa.

Considerando-se o modelo para explicar a probabilidade de formação de conluio por parte da companhia aérea TAM, observa-se, pela Tabela 3, que a estatística razão de verossimilhança $(L R)$ foi de $-41,256$, significativa a $1 \%$. Desse modo, tem-se que as variáveis incluídas no modelo são conjuntamente significativas e, assim, são capazes de explicar tal fenômeno. O modelo estimado conseguiu prever corretamente 85,29\% das observações (Count $R^{2}=85,29$ ). 
Apesar da significância conjunta, individualmente somente a variável preço médio das concorrentes (pmec) foi significativa em nível de 10\%. Além disso, apresentou sinal diferente do esperado a priori, uma vez que se espera que quanto maior o preço médio das concorrentes maior a probabilidade de formação de conluio e não o contrário. As demais variáveis não foram importantes para a explicação desse fenômeno para a amostra analisada. Dado um preço médio das concorrentes da TAM de $\mathrm{R} \$ 221,27$, tem-se que um aumento de $\mathrm{R} \$ 1,00$ no custo médio da passagem de suas concorrentes levaria a uma redução de 0,1144 p.p. na probabilidade de formação de conluio por parte dessa empresa.

De modo geral, a probabilidade de formação de conluio por parte da companhia aérea TAM, estimada pelo modelo, é de aproximadamente 13,64\%, no período analisado (Tabela 3), sendo essa probabilidade maior do que aquela estimada para a companhia aérea GOL. Essa conduta é condizente com a posição da TAM como líder do mercado em análise.

No modelo que explica a participação da TAM em uma guerra de preços, a estatística razão de verossimilhança (LR) apresentou-se significativa em nível de $1 \%$ de probabilidade. Isso sugere que as variáveis incluídas no modelo são, conjuntamente, capazes de explicar a probabilidade de essa companhia participar de uma guerra de preços. Porém, individualmente, somente a variável dummy $c_{t-1}$ foi estatisticamente significativa para explicar a probabilidade da TAM em participar de uma guerra de preços. Com base nos resultados obtidos, para o período em análise, o fato de a TAM estar participando de um conluio em um determinado mês faz com que aumente em média 35,21 p.p. a probabilidade de disparada de guerra de preços por parte dessa companhia no mês seguinte, ceteris paribus (Tabela 3).

Observou-se que o modelo estimado conseguiu prever corretamente $69,61 \%$ das observações, sendo a probabilidade da TAM praticar/estar em uma guerra de preços nesse período foi de aproximadamente $33,43 \%$.

Por fim, os resultados mostraram que os determinantes de guerra de preços por parte das duas companhias analisadas não foram os mesmos para o período em análise e, provavelmente, não serão em outros períodos.

\section{CONCLUSÕES}

Neste trabalho buscou-se identificar os determinantes da formação de conluio e de disparada de guerra de preços por parte das duas principais companhias aéreas brasileiras, TAM e GOL, na ligação Rio de Janeiro - São Paulo, no período de março de 2002 a setembro de 2010 . 
Como principais resultados tem-se que os fatores determinantes desses dois fenômenos são diferentes para cada companhia aérea. Além disso, tem-se que a TAM, detentora da maior parcela do mercado em todo o período em análise, tem maior probabilidade de formar conluio que a GOL.

Por outro lado, os modelos estimados mostram que a GOL tem maior probabilidade de entrar em uma guerra de preços do que em um conluio. $\mathrm{O}$ fato de ter participado de um conluio no mês anterior foi o principal determinante para a entrada da GOL em uma guerra de preços. A GOL se consolidou como líder em baixo custo no mercado e, ao entrar com tarifas reduzidas, "obrigou" as demais companhias a promover descontos por diversas vezes no período estudado.

Por outro lado, a probabilidade da TAM praticar guerra de preços poderia ser mais bem explicada pela inclusão de outras variáveis, uma vez que apenas o fato de ter participado de um conluio no mês anterior foi uma variável importante (significativa) para a explicação desse fenômeno no modelo estimado. Porém, este trabalho ficou limitado à inclusão de variáveis pela pouca disponibilidade de dados. Entretanto, futuras pesquisas podem expandir a análise incluindo outras variáveis, como, por exemplo, o contato multimercado, uma vez que quando as empresas competem em diferentes mercados, há maior tolerância entre elas devido ao fato de que a empresa tem possibilidade de responder a ações ou ataques de uma rival, não apenas no mercado desafiado, mas também em outros mercados em que ambas competem.

\section{REFERÊNCIAS}

ABREU, D.; PEARCE, D.; STACCHETTI, E. Optimal cartel equilibria with imperfect monitoring. Journal of Economic Theory, v. 39, n. 1, p. 251-269, 1986.

AGÊNCIA NACIONAL DE AVIAÇÃO CIVIL - ANAC. Anuário Estatístico do Transporte Aéreo. Brasília: ANAC, 2010.

AGÊNCIA NACIONAL DE TRANSPORTES TERRESTRES - ANTT. Departamento de Transportes Rodoviários. Anuário Estatístico do Transporte Rodoviário Interestadual e Internacional Coletivo de Passageiros 2008 - Ano base 2007. Brasília: ANTT, 2008. Disponível em: <http://www.antt.gov.br/passageiro/anuarios/anuario2008/default.asp>. Acesso em 07 de fevereiro de 2012.

Anuário Estatístico do Transporte Rodoviário Interestadual e Internacional Coletivo de Passageiros 2007 - Ano base 2006. Brasília: ANTT, 2007. Disponível em: <http://www. antt.gov.br/passageiro/anuarios/anuario2007/default.htm $>$. Acesso em 07 de fevereiro de 2012.

. Anuário Estatístico do Transporte Rodoviário Interestadual e Internacional Coletivo de Passageiros 2006 - Ano base 2005. Brasília: ANTT, 2006. Disponível em: <http://www. 
antt.gov.br/passageiro/anuarios/anuario2006/default.htm>. Acesso em 07 de fevereiro de 2012.

Departamento de Transportes Rodoviários. Anuário Estatístico do Transporte Rodoviário Interestadual e Internacional Coletivo de Passageiros 2005 - Ano base 2004. Brasília: ANTT, 2005. Disponível em: <http://www.antt.gov.br/passageiro/anuarios/ anuario2005/pdf/default.pdf $>$. Acesso em 07 de fevereiro de 2012.

- Departamento de Transportes Rodoviários. Anuário Estatístico do Transporte Rodoviário Interestadual e Internacional Coletivo de Passageiros 2004 - Ano base 2003. Brasília: ANTT, 2004. Disponível em: <http://www.antt.gov.br/passageiro/anuarios/ anuario2004/PDF/default.pdf $>$. Acesso em 07 de fevereiro de 2012.

Departamento de Transportes Rodoviários. Anuário Estatístico do Transporte Rodoviário Interestadual e Internacional Coletivo de Passageiros 2003 - Ano base 2002. Brasília: ANTT, 2003. Disponível em: <http://www.antt.gov.br/passageiro/anuarios/ anuario2003/PDF/default.pdf $>$. Acesso em 07 de fevereiro de 2012.

Departamento de Transportes Rodoviários. Anuário Estatístico do Transporte Rodoviário Interestadual e Internacional Coletivo de Passageiros 2002 - Ano base 2001. Brasília: ANTT, 2002. Disponível em: < http://www.antt.gov.br/passageiro/anuarios/ anuario2002/PDF/default.pdf $>$. Acesso em 07 de fevereiro de 2012.

- Departamento de Transportes Rodoviários. Anuário Estatístico do Transporte Rodoviário Interestadual e Internacional Coletivo de Passageiros 2001 - Ano base 2000. Brasília: ANTT, 2001. Disponível em: <http://www.antt.gov.br/passageiro/anuarios/ anuario2001/default.htm>. Acesso em 07 de fevereiro de 2012.

BUSSE, M. R. Firm financial conditions and airline price wars. The RAND Journal of Economics, v. 33, n. 2, p. 298-318, 2002.

CAMERON, A. C.; TRIVEDI, P. K. Microeconometrics: Methods and Applications. Cambridge, UK: Cambridge University Press, 2005.

FERREIRA, N. Discussão das abordagens teóricas na investigação de práticas de concorrência predatória no transporte aéreo. Revista de Literatura dos Transportes, v. 1, n. 2, p. 47-69, 2007.

FLORES, G. A. Cartel: teoria econômica e a prática antitruste no Brasil. Dissertação (Mestrado em Economia) - Centro de Pós-Graduação em Economia, Universidade Federal Fluminense, Niterói, 2007.

FRIEDMAN, J. A Non-cooperative equilibrium for supergames. Review of Economic Studies, v. 38, p. 1-12, 1971.

GREEN, E. J.; PORTER, R. Noncooperative collusion under imperfect price competition. Econometrica, v. 52, p. 87-100, 1984.

HEIL, O.P.; HELSEN, K. Toward an understanding of price wars: their nature and how they erupt. International Journal of Research in Marketing, v. 18, p. 83-98, 2001.

HILL, R. C.; GRIFFITHS, W. E.; JUDGE, G. G. Econometria. 2. ed. São Paulo: Saraiva, 2003.

KREPS, D. M. Game Theory and economic modeling. Oxford: Clarendon Press, 1990. 
LEVENSTEIN, M. C.; SUSLOW, V. Y. What determines cartel success. Journal of Economic Literature, v. 44, p. 43-95, 2006.

MADDALA, G. S. Introduction to econometrics. 2. ed. New York: Macmillan Publishing Company, 1992.

MORRISON, S. A.; WINSTON, C. Causes and consequences of airline fare wars. Brookings Papers on Economic Activity, p. 85-131, 1996.

OLIVEIRA, A. V. M. A alocação de slots em aeroportos congestionados e suas consequências no poder de mercado das companhias aéreas. Revista de Literatura dos Transportes, v. 4, n. 2, p. 5-49, 2010.

OSBORNE, M.; RUBINSTEIN, A. A curse in game theory. Boston: MIT Press, 1994.

PORTER, R. Optimal cartel trigger price strategy. Journal of Economic Theory, v. 29, p. 313-338, 1983.

ROSS, L. B. When will an airline stand its ground? An analysis of fare wars. International Journal of the Economics of Business, v. 4, n. 2, p. 109-127, 1997.

ROTEMBERG, J. J.; SALONER, G. A supergame-theoretic model of business cycles and price wars during booms. American Economic Review, v. 76, p. 390-407, 1986.

SILVEIRA, J. M.; OLIVEIRA, A. V. M. An empirical game-theoretical approach to model a price war in the Brazilian airline industry. Revista de Literatura dos Transportes, v. 2, n. 1, p. 7-20, 2008.

TUROLLA, F. A.; LOVADINE, D.; OLIVEIRA, A. V. M. Competição, colusão e antitruste: estimação da conduta competitiva de companhias aéreas. Revista Brasileira de Economia, v. 60, n. 4, p. 425-459, 2006.

VASSALLO, M. D. Simulação de fusão com variações de qualidade no produto das firmas: aplicação para o caso do code-share Varig-TAM. Revista de Literatura dos Transportes, v. 4, n. 2, p. 50-100, 2010.

ZEIDAN, R. M.; RESENDE, M. Colusão ótima com monitoramento imperfeito: teste do modelo de Abreu-Pearce-Stachetti para os mercados brasileiros de cimento. Economia Aplicada, v. 14, n. 1, p. 41-50, 2010.

ZHANG, Y; ROUND, D. K. Price wars and price collusion in China's airline markets. International Journal of Industrial Organization, 2010. (Article in Press). 